NBER WORKING PAPER SERIES

\title{
DETERMINANTS OF REAL HOUSE PRICE DYNAMICS
}

\author{
Dennis R. Capozza \\ Patric H. Hendershott \\ Charlotte Mack \\ Christopher J. Mayer \\ Working Paper 9262 \\ http://www.nber.org/papers/w9262
NATIONAL BUREAU OF ECONOMIC RESEARCH
1050 Massachusetts Avenue
Cambridge, MA 02138

October 2002

We thank Steven Van Emmerik and the participants in seminars at Columbia University, the University of Michigan, and the ASSA meetings for helpful comments. The views expressed herein are those of the authors and not necessarily those of the National Bureau of Economic Research.

(C) 2002 by Dennis R. Capozza, Patric H. Hendershott, Charlotte Mack, and Christopher J. Mayer. All rights reserved. Short sections of text, not to exceed two paragraphs, may be quoted without explicit permission provided that full credit, including (C) notice, is given to the source. 
Determinants of Real House Price Dynamics

Dennis R. Capozza, Patric H. Hendershott, Charlotte Mack, and Christopher J. Mayer

NBER Working Paper No. 9262

October 2002

JEL No. G120, R310

\section{$\underline{\text { ABSTRACT }}$}

We explore the dynamics of real house prices by estimating serial correlation and mean reversion coefficients from a panel data set of 62 metro areas from 1979-1995. The serial correlation and reversion parameters are then shown to vary cross sectionally with city size, real income growth, population growth, and real construction costs. Serial correlation is higher in metro areas with higher real income, population growth and real construction costs. Mean reversion is greater in large metro areas and faster-growing cities with lower construction costs. Empirically, substantial overshooting of prices can occur in high real construction cost areas, which have high serial correlation and low mean reversion, such as the coastal cities of Boston, New York, San Francisco, Los Angeles and San Diego.

Dennis R. Capozza

University of Michigan Business School

Ann Arbor, MI 48109

capozza@umich.edu

Charlotte Mack

University of Michigan

Ann Arbor, MI 48109

cym@umich.edu
Patric H. Hendershott

University of Aberdeen Business School

Old Aberdeen AB24 3UF

Scotland, UK

and NBER

phh3939@uslink.net

Christopher J. Mayer

Wharton School

University of Pennsylvania

Philadelphia, PA 19104-6330

mayerc@wharton.upenn.edu 


\section{Determinants of Real House Price Dynamics}

Numerous studies of a variety of asset markets have now documented the existence of short horizon serial correlation and long horizon mean reversion in asset prices. Among asset markets, the most heavily researched is the equity market. Two examples include Fama and French (1988) and Poterba and Summers (1988). Using different methodologies both studies find significant evidence of mean reversion at long horizons. For example, Fama and French conclude that "predictable variation is estimated to be about 40 percent of 3-5 year return variances for portfolios of small firms." Time varying equilibrium expected returns and investor overreaction have been proposed as possible explanations. ${ }^{2}$

The focus of our research is the U.S single-family housing market. As has been done for other asset types, earlier studies of housing have documented both serial correlation (Case and Shiller, 1989; Abraham and Hendershott, 1993;) and mean reversion (Abraham and Hendershott, 1996; Capozza and Seguin, 1996; Malpezzi, 1999). From these studies and from the observed behavior of housing prices in regional markets, it is clear that the extent of correlation or reversion varies with location. For example, Abraham and Hendershott (1996) document a significant difference in time series properties between coastal and inland cities. The logical

\footnotetext{
${ }^{1}$ A recent study that models "fundamental" value using dividends and earnings is Chiang, Davidson and Okunev (1997).

${ }^{2}$ There is a long literature in international trade that explains exchange rate movements as reversion to purchasing power parity (fundamental value). A recent example that uses panel data is Frankel and Rose (1996). They find "strong evidence of mean reversion that is similar to that from long time-series."
} 
questions to ask are what variables other than the coast might affect time series properties (or what variables might "coast" proxy for) and why do regions react differently to economic shocks? ${ }^{3}$

We use a large panel data set for 62 US metropolitan areas from 1979 to 1995. The data set includes economic, demographic, and political variables for each of the metro areas. We explore two kinds of hypotheses for serial correlation and mean reversion: information or transaction based explanations and supply based theories. Housing is highly heterogeneous so that participants have difficulty assessing the instantaneous "true" price for any given property. In general (Quan and Quigley, 1991), an optimal "appraisal" weights current and past transactions prices of similar properties. As a result transaction frequency can affect the rate of information dissemination in a housing market. Transaction frequency also affects reservation prices in search models of the housing market (Wheaton, 1990). Whenever economic or demographic variables affect transaction frequency, some metro areas may react either faster or with more amplitude to a given economic shock than other areas.

Further, any given positive economic shock will be easier for an area to absorb if the housing stock can be increased quickly and at low cost. Therefore we hypothesize that variables proxying for the cost and difficulty of adding to the supply of housing should affect the time series properties of housing prices. To preview the

\footnotetext{
${ }^{3}$ A recent study that is the first to attempt to explain differences among regions is Lamont and Stein (1999). They find that "where homeowners are more leveraged . . . house prices react more sensitively to city-specific shocks."
} 
conclusions we find evidence that both information dissemination and supply factors influence the dynamics of housing prices.

Our three contributions are first to provide additional evidence on serial correlation and mean reversion in house prices using a much larger panel data set than previously. Our results are consistent with earlier estimates but lie at the upper end of their range. Secondly we analyze the difference equation implied by serial correlation and mean reversion and show that the estimates for most metro areas lie in the damped cyclical range. Third and most importantly, we model and estimate equations relating the extent of serial correlation and mean reversion to possible determinants. We explore the role of information dissemination, supply constraints, and backward-looking expectation formation on market dynamics.

In the next section we develop the difference equation and the empirical specification. The third section describes the panel data set we use for our estimates and the fourth section discusses the empirical results. Simulation results indicate the wide variation in possible dynamics. The final section concludes with suggestions for future research and policy implications.

\section{Model}

It is assumed that in each time period, $t$, and in each metro area there is a fundamental value for housing that is determined by economic conditions.

$$
P_{t}^{*}=p\left(\boldsymbol{X}_{t}\right)
$$

where $P^{*}$ is the $\log$ of real fundamental value in the metro area and $\boldsymbol{X}_{t}$ is a vector of exogenous explanatory variables. 
Following Abraham and Hendershott (1996), value changes are governed by reversion to this fundamental value and by serial correlation according to

$$
\Delta P_{t}=\alpha \Delta P_{t-1}+\beta\left(P_{t-1}^{*}-P_{t-1}\right)+\gamma \Delta P_{t}^{*}
$$

where $P_{t}$ is the log of real house values at time $t$ and $\Delta$ is the difference operator. The first term on the right in (2) is the serial correlation term. $\alpha$ is the serial correlation coefficient. The second term causes reversion to fundamental value. $\beta(0<\beta<1)$ is the rate of adjustment to fundamental value. The third term allows for immediate partial adjustment to fundamentals. Partial adjustment implies that $0<\gamma<1$.

Equation (2) can be rewritten in difference equation form as

$$
P_{t}-(1+\alpha-\beta) P_{t-1}+\alpha P_{t-2}=\gamma P_{t}^{*}+(\beta-\gamma) P_{t-1}^{*}
$$

The dynamic behavior of (3) is studied by applying the "z-transform," $b^{n}=P_{n}$, and then analyzing the resulting "characteristic equation" of the difference equation in (3) given by

$$
b^{2}-(1+\alpha-\beta) b+\alpha=0
$$

Figure 1 summarizes the analysis. In the figure, the curve defined by

$$
(1+\alpha-\beta)^{2}=4 \alpha
$$

divides the parameter space into a cycles region below the curve and a no cycle region above the curve. The vertical line at $\alpha=1$ divides the parameter space into an explosive region to the right of the line and a damped region to the left. When the autocorrelation coefficient is above unity deviations from steady state are magnified 
over time and the path of values diverges from fundamentals.

From Figure 1 it is clear that many kinds of dynamic behavior can be accommodated within this simple model. Loosely speaking, as the serial correlation coefficient, $\alpha$, increases, the amplitude and persistence of cycles increases. As the reversion coefficient, $\beta$, increases, the frequency and amplitude of the cycle increases.

\section{The Hypotheses}

We wish to explore the causes of differences in the dynamic response of metro areas to shocks to the local economy. In the context of the model, these differences will appear as different estimates of alpha and betạ. Therefore we rewrite (2) as

$$
\Delta P_{k t}=\left(\alpha+\sum_{i} \alpha_{i}\left(Y_{k i t}-Y_{i}^{*}\right)\right) \Delta P_{k, t-1}+\left(\beta+\sum_{i} \beta_{i}\left(Y_{k i t}-Y_{i}^{*}\right)\right)\left(P_{k, t-1}^{*}-P_{k, t-1}\right)+\gamma \Delta P_{k t}^{*}
$$

where the $Y_{i}$, which may include a subset of $\boldsymbol{X}$, are independent variables, $\mathrm{Y}^{*}$ represents the mean value, and $k$ indexes cities.

\section{Information Costs}

An important issue is the choice of the $Y_{i}$. First we consider the role of information dissemination. In real estate markets information costs are high, transactions are infrequent, and the product is highly heterogeneous. As a result participants have difficulty assessing the current value of properties and may have to use sales distant in time or location for setting reservation prices (Quan and Quigley 1991). Markets with a higher level of transactions have lower information costs and thus prices should adjust more quickly to their fundamental value, i.e., mean 
reversion should be greater. We include population as a measure of the number of transactions and thus information costs.

Another measure of the importance of information derives from models of search in housing markets (Wheaton, 1990, and DiPasquale and Wheaton, 1996). In these models, a positive real income shock causes existing homeowners to be under housed and thus to move or renovate to increase their housing consumption to the new equilibrium levels. When transactions volume increases, search costs decline and the reservation price for both buyers and sellers increases. Once the adjustment to new housing needs has occurred, transactions volume falls back to its long-run level. In terms of our model, higher real income growth should proxy for higher transactions volume and lower search costs, which should lead to faster mean reversion.

\section{Construction Costs}

A second set of hypotheses relate to the real cost of new housing. We identify possible cost effects both within a given market and across markets. Across different markets high real construction costs may serve as indicators of factors that reduce the short-run responsiveness of supply to demand shocks. This may be the case if high real costs are correlated with unpriced supply restrictions. Regulation is an example of one such restriction. Stricter regulations on new development such as minimum lot size or regulatory-induced lags have two effects; they increase the cost of new housing (both in an absolute terms, and relative to existing housing) and they reduce the ability of builders to respond quickly to demand shocks. Mayer and Somerville 
(2000) show that construction is less responsive to price shocks in markets with more local regulation.

In the context of our model, we hypothesize that higher real construction costs are correlated with slower mean reversion and more serial correlation. The latter effect may be especially controversial. New supply serves to reduce the degree of serial correlation because, in the absence of a futures market, it is one way that participants can arbitrage inefficient pricing. In markets where supply can respond quickly to price shocks, serial correlation should be lower.

\section{Expectations}

Finally, we look for evidence of "euphoria" (Capozza and Seguin, 1996), or backward-looking expectations as an indicator of the degree of serial correlation. Case and Shiller $(1988,1989)$ and Shiller (1990) posit that serial correlation in real estate markets is partially due to backwards-looking expectations of market participants. ${ }^{4}$ Case and Shiller (1988) have conducted surveys of recent buyers, showing that buyers in booming markets have greater expected house price appreciation than buyers in a control market. Buyers in the booming market indicate that they treat the purchase of a home more as an investment, and discuss housing market changes more frequently. By contrast, buyers in the control market spend less time discussing the housing market, and place more weight on the consumption value of a home, as opposed to its investment value. To the extent that these expectations are incorporated into observed transaction prices, strong markets should have more 
serial correlation than markets with slower income growth. We include real income growth as an indicator of the state of the economic cycle and long-run population growth is included to measure the role of inertia or backward-looking expectations in serial correlation.

To summarize, higher real income and population growth and a high level of real construction costs are expected to increase serial correlation. Higher real income growth, larger metro area size (population) and a lower level of real construction costs should increase mean reversion. We test these hypotheses below.

\section{Data}

Our data are a subset of the large panel data set described in Capozza, Kazarian, and Thomson (1997). The data for this study cover 62 metro areas for the 17 years from 1979-1995. Included among the variables are median house prices, population, personal income, real construction costs, a land supply index, the consumer price index, mortgage rates, property tax rates, and income tax rates. The data are annual series with the exception of income tax rates, which derive from the decennial census. The land supply index, a measure of the percentage of the land around the city that is available for development, also varies across cities, but not over time. (See Rose 1989 and Capozza and Seguin 1996 for more detail on this variable.) Table 1 provides summary statistics on the data series.

\footnotetext{
${ }^{4}$ Hendershott (2000) finds evidence of backwards-looking expectations in the Sydney office market.
} 


\section{House Prices}

Two variables require more discussion. The first is the median house price series. There is considerable debate over the merits of using median house price data versus repeat sales data. This study uses the NAR median price series because of its long history and extensive coverage of metro areas. Repeat sales data were available at the regional level from the FHLMC but for only a limited number of MSAs. The median and the repeat sales price series exhibit similar overall patterns, but there are timing differences, especially in the Northeast and the Southeast. The Pearson product-moment correlations of the price changes are $0.59,0.73,0.89,0.88$ and 0.92 for the Northeast, Southeast, North Central, Southwest and West regions respectively. The correlations of first differences suggest there will not be a large difference between empirical estimates from the two data series. We report the results of a robustness check using the FHLMC data below.

Because our model estimates the long-run real house price level in the first stage, we take advantage of the level differences within a city obtained with median prices. Repeat sales indexes only measure relative prices within a city over time, but not across different cities, and thus are not well suited for estimation procedures that attempt to exploit the cross-sectional variation by using the absolute dollar value of housing.

Neither median nor repeat sales data are fully quality adjusted. The upward quality drift in the median prices is about $2 \%$ per year (Hendershott and Thibodeau, 1990) and occurs both because new houses of above average quality are added and because existing houses are renovated. In the typical metro area, much of the quality 
drift arises from renovations. Repeat sales data include only existing houses so that only the drift from renovations applies. Since typical repeat sales procedures attempt to exclude or adjust for houses that increase in size, the quality drift is mitigated. Many existing houses are renovated soon after purchase. For our purposes, a constant rate of upward drift will not affect the results since we include dummy variables for each year of the sample. A more important issue is systematic changes in the quality of the median house over an economic cycle. If the quality of the median house is systematically different near peaks than it is near troughs, the median price series will over or under estimate cyclical movements. However, as long as this bias is constant across cities, it will not impact our estimates of the factors that affect the cyclicality of prices.

User Cost

The user cost (UC) is a derived variable. It is an attempt to capture the after tax cost of home ownership. Our calculation adjusts ownership costs for taxes and appreciation rates:

$$
\mathrm{UC}=(\text { Mortgage rate }+ \text { Property tax rate) }(1-\text { Income tax rate })-\text { Inflation rate }
$$

The source and definition of all the right hand side variables appear in Appendix A. The metropolitan areas included in the study are listed in Appendix B. Two data issues are worth noting. First, only the tax rate variables vary cross-sectionally so that user cost is mainly a time series variable. Mortgage rates and inflation rates are national series. Second, since the expected appreciation of housing is being measured by the national inflation rate (CPI) during the previous year, the variation in 
expectations by location, which may be substantial, is not incorporated.

Clearly more sophisticated measures of user cost are possible but beyond the scope of this research.

\section{Empirical Estimates}

Our empirics are developed in three stages. First, we estimate the long run price relationship, equation (1). Second, we estimate an adjustment relationship, equation (2), where the serial correlation and mean reversion variables are added to the model. Lastly, we allow the serial correlation and mean reversion coefficients to vary over time and space by estimating equation (6).

\section{Preliminaries: The Long Run Relationship}

We begin by fitting a long-run equilibrium equation for real house price levels in a metro area using the annual panel data described in the previous section. Following the urban asset pricing models of Capozza and Helsley $(1989,1990)$ and Capozza and Sick (1994), equilibrium real house prices are modeled as a function of the size of a metro area (population level and real median income), the real construction cost of converting land from agricultural use to new residential structures, an expected growth premium, and the user cost of owner-occupied housing. The equation is estimated in two versions, first using OLS and second using a panel data estimator that controls for both year and metro area fixed effects. These fixed effects will capture any systematic differences in the average quality of housing across cities or over time. All variables are measured in logs.

Estimates from the above equation are given in Table 2. All variables in model 1 of Table 2 have the expected sign, and many coefficients have the expected 
magnitude. In particular, real median house prices are positively related to total population, real median income, an index of real construction costs, and the 5year growth rate in population (proxying for the long-run expected growth rate of population), and are negatively related to the user cost of housing and the land supply index. ${ }^{5}$ The coefficients suggest reasonable elasticities. For example, the coefficient on real construction cost is 1.1 in model 1.1 and 1.2 in model 2 when fixed effects are included in the specification. Neither value is statistically different from the theoretical prediction of 1.03 at the 5 percent level. (The mean index value is 0.97 ; therefore a .01 unit increase in the cost index leads to a $1.03(=1 / 0.97)$ percent increase in prices.) The coefficients on real income suggest that a one percent rise in a metro area's real income leads to almost a half percent increase in real median house prices, either because the prices of more desirable locations are bid up or because consumers improve their existing units. ${ }^{6}$ The amount of developable land around a city, measured by the land supply index, has a negative and significant effect on the real price level, as would be expected.

The real price elasticity with respect to city size (population) in model 2 is 0.15 , smaller than would be obtained from a standard monocentric city urban model. However, the existence of fringe cities should lower the expected size of the population coefficient relative to a standard urban model. Long-run growth has a

\footnotetext{
${ }^{5}$ Blanchard and Katz (1992) show that the growth rate of population is persistent over time using state-level data over several decades.

${ }^{6}$ This is consistent with earlier work (see Bourassa, Hendershott and Murphy, 2001).
} 
large impact on real price levels; a one percent increase in the population growth rate over the last five years leads to $1 \frac{1}{2}$ percent higher real house price.

In both models 1 and 2, the coefficients on population level and growth are similar. Perhaps due to limited cross-sectional variation, the user cost coefficients of -0.04 and -0.09 are statistically different from zero, but far from the value of -1.0 predicted by theory. ${ }^{7}$ In the empirical work that follows, we use model 2. F-tests of the significance of the time and metro area effects reject that these fixed effects equal zero at the 0.001 confidence level.

Dynamics: the Adjustment Equation

The second stage analysis uses the estimates of $P^{*}$ from the first stage equation to "anchor" the estimates of price changes. In particular, we estimate equation (2) where $\alpha$ represents the degree of serial correlation, $\beta$ is the extent of mean reversion, and $\gamma$ is the contemporaneous adjustment of prices to current shocks. If house prices adjusted instantaneously to local economic shocks and real estate markets were perfectly efficient, $\gamma$ would equal 1 , and $\alpha$ would equal 0 (theory has no prediction about the estimated value of $\beta$ because actual house prices would never deviate from their long-run fundamentals.) However, abundant academic research has shown that $\alpha$ is positive and economically and statistically significant. For example, Case and Shiller (1989) estimate that annual serial correlation in their

\footnotetext{
${ }^{7}$ In a study using similar cities but decennial data only (1970, 1980 and 1990), Capozza, Green and Hendershott (1996) find a price elasticity of -0.8 , insignificantly different from 1.0 .
} 
sample of 4 cities ranges from 0.25 to $0.5 .^{8}$ Abraham and Hendershott (1993) obtain an estimate of 0.4 on a panel of 29 cities. When the cities are divided roughly in half, the estimate is 0.5 for the coastal cities versus 0.2 for the inland cities (Abraham and Hendershott, 1996). When house prices converge to their fundamental values in the long run, $\alpha>0$ implies. $\beta>0$.

Estimates from this second stage equation are given in the Model 1 of Table 3. To control for possible omitted local factors that might cause differential appreciation rates, we initially included fixed effects for all MSAs. The subsequent regressions do not include these fixed effects in the second stage because an F-test of the significance of these factors does not allow for rejection at conventional confidence levels and the empirical work is little changed by their exclusion.

The empirical results in Table 3 are consistent with the previous real estate literature, and suggest slow responses for real estate relative to other assets. The immediate adjustment coefficient, $\chi$, for example, suggests that current house prices adjust to 52 percent of the value of a shock to predicted (or fundamental) house price levels in the year of the shock. In addition, house prices also exhibit strong serial correlation, with a coefficient of 0.33 . This estimate is consistent with those in Abraham and Hendershott and Case and Shiller. Furthermore, our estimates show

\footnotetext{
${ }^{8}$ Case and Shiller also note that the construction of repeat sales indexes induces spurious serial correlation in estimators derived from a single sample of houses. Such a bias does not affect our sample because we use median sales prices. Even with repeat sales indexes, however, spurious serial correlation would only bias the intercept in the third stage, not the coefficients on other explanatory variables.
} 
that house prices take a long time to converge to their long-run values.

Actual prices converge only 25 percent $(=\beta)$ of this difference every year.

Of course the degrees of serial correlation and mean reversion are not constant across markets. Case and Shiller find the degree of serial correlation varies across four markets and Abraham and Hendershott (1996) report that cities on the coasts (e.g., Boston, New York, San Francisco, Los Angeles) have had far more severe real estate cycles, owing to both higher serial correlation and lower mean reversion, than cities in the Midwest (e.g., Chicago, Milwaukee, Cleveland, Detroit).

\section{Endogenous Dynamic Adjustment}

In the third stage, we estimate possible determinants of the degree of serial correlation and mean reversion by interacting variables derived from hypotheses described earlier - population growth (information dissemination), real income growth (search costs, behavioral models), and real construction costs (supply elasticities) - with the serial correlation and mean reversion variables, as in equation (6). That is, serial correlation and mean reversion are allowed to vary both over time and over space.

These estimates, presented in models 2 and 3 in Table 3, provide significant evidence consistent with all three of the hypotheses. The most striking results are the determinants of serial correlation. High real construction costs and faster growth in both population and real income are associated with greater autocorrelation. A onestandard deviation shock of two percent to either real income or the 5-year growth rate of population leads to a 10 percent increase in serial correlation (a third of the overall effect in model 1). Both of these results suggest that house prices exhibit 
much more serial correlation, and thus a greater likelihood of overshooting their fundamental values, in metro areas in the midst of a strong economic expansions.

Differences across MSAs in real construction costs lead to economically and statistically significant differences in serial correlation. For example, an increase in real construction costs of 10 percent would increase serial correlation by 15 percentage points--one-half of the average serial correlation coefficient in model 1. To the extent that high construction costs are related to inelastic supply, the costs may be indicative of factors that do not allow the supply of new houses to adjust quickly to demand shocks. Regulation or geography are two examples of such factors. Many types of land use regulation raise development costs and make it more difficult for developers to respond to market signals. Mayer and Somerville (2000), for example, show that higher levels of regulation lead to fewer permits and lower supply elasticities. Reduced land availability, either because of historic development or small farms at the periphery of a city, may make land assembly more difficult and expensive.

In model 3, we explore the extent to which geography (the land supply index) is related to the construction cost result reported earlier. However, the coefficient on the land supply interaction is the opposite of that predicted by theory and not statistically significant.

While the results on the impact of various factors explaining the degree of mean reversion are consistent with the hypotheses, they are weaker in terms of 
economic and statistical significance. The interaction coefficients are statistically significant at the 5 or 10 percent levels. Metro area size is positively related to the degree of mean reversion, an effect that would be predicted from search models with imperfect information. Information about demand shocks is easier to discern in thicker markets in which comparable units sell more often. Thus prices should adjust more quickly to their fundamental levels because homeowners can more easily determine a price for a house that incorporates latest market information. The estimates show that prices revert to their mean 6 percentage points faster in a metro area that is twice as large as a comparison metro area.

Also consistent with search models, higher income growth leads to greater mean reversion. As with population, the economic impact of differences in income growth is moderate. A two-percentage point increase in the growth rate of income leads to a three percent increase in mean reversion (10 percent of the total effect). Finally, a 10 percent increase in real construction costs lowers mean reversion by four percentage points.

\section{Partial Adjustment, Serial Correlation, Mean Reversion and Cycles}

Evidence that real estate markets do not immediately adjust to changes in fundamentals and exhibit serial correlation has often been cited as showing that real estate price trends are caused by inefficiencies in real estate markets. That is, inefficiencies in real estate markets lead to prices that do not immediately incorporate all market information and thus exhibit smooth behavior. Others (e.g., Abraham and Hendershott, 1996) have gone further, arguing that these inefficiencies have caused 
house prices in some areas to significantly "overshoot" their fundamental values, leading to large declines as prices return to their long-run values.

The behavior of house prices in equation (2) is determined by three factors (coefficients): partial adjustment to fundamentals $(\gamma)$, serial correlation $(\alpha)$ and mean reversion ( $\beta$ ) For there to be significant "overshooting." a minimum requirement is that a combination of fast adjustment and serial correlation exist. Without the former, serial correlation just helps prices to more rapidly rise or fall to the new equilibrium; without the latter, there is nothing to generate overshooting. And even if this combination exists, a series of positive shocks is necessary to get significant overshooting, and a low degree of mean reversion is required or any overshooting will quickly be reversed.

To illustrate these points, we have simulated a six-year period of rapid (four percent) growth in equilibrium real house prices, ending with the equilibrium being 26.5 percent higher. We simulate actual real price and the percentage overshootingthe percentage difference between actual and equilibrium real price. The maximum overshooting is given for combinations of $\gamma(0.5$ and 0.75$), \alpha(0.5,0.667,0.75$ and $0.9)$ and $\beta(0.1,0.3$ and 0.5$)$ in Table 4. As can be seen, overshooting is less than three percent for $\gamma=\alpha=0.5$ irrespective of the value of $\beta$. If either. $\gamma$ is raised to 0.75 or $\alpha$ to 0.667 , overshooting of 8 percent occurs if mean reversion is very low $(\beta=$ 0.1). Double digit overshooting requires even higher values of $\gamma$ and/or $\alpha$ or even less mean reversion. To repeat, only if we have rapid adjustment to fundamentals, 
high serial correlation, and low mean reversion can significant overshooting occur. ${ }^{9}$ The serial correlation and mean reversion estimates in model 1 are too low and high, respectively, for the existence of significant overshooting.

On the other hand, the estimates of model 2 suggest possible large overshooting. Rapid growth is not likely to do it because growth raises both autocorrelation and mean reversion, the former contributing to overshooting but the latter limiting it. However, high real construction costs both increase autocorrelation and lower mean reversion. And real construction costs are much higher in some areas (the large coastal cities) than in others. More specifically, real construction costs are, on average, forty percent higher during our sample period in Boston, New York, San Francisco, Los Angeles, Orange County and San Diego than in the rest of the sample. For these six cities, autocorrelation is 0.9 and mean reversion is 0.1 according to our estimates. Accordingly, the simulations in Table 4 suggest the likelihood of 27 percent overshooting in response to six years of four percent real growth.

\section{Robustness Tests}

In addition to the specifications reported above, a number of alternative specifications were tried but not reported in the tables. With the available repeat sales price data as the dependent variable in the stage 1 and 2 regression, the results were quite economically similar to the equations in Table 2 but with smaller sample

sizes the independent variables were less statistically significant. In the second stage 
regressions, the repeat sales data exhibit more serial correlation $(0.55$ versus $0.33)$ and less mean reversion ( 0.15 versus 0.25$)$.

As indicated earlier alternative panel error specifications were also tried and tested against the models presented. Finally, because of the importance of supply in the stage three regressions, additional variables on the regulatory structure for housing supply were compiled and tested. These variables include data on local fees payable by developers (use fees and total fees) as well as the average and maximum times needed in the approval process. None of these regulatory variables was statistically significant at the usual levels in the stage three regressions.

\section{Conclusion}

Our results show that variation in the cyclical behavior of real house prices across metropolitan areas is due to more than just variation in local economies. House prices react differently to economic shocks depending on such factors as growth rates, area size, and construction costs. The results are much stronger statistically and economically - in explaining serial correlation than mean reversion. While the average city in the sample has an autocorrelation coefficient of 0.49 , a city with a zero growth rate of population and real income and relatively low real construction costs (index $=0.90$ ) would have an autocorrelation coefficient of just 0.23 . And a city with 4 percent growth in population and real income, and high real construction costs (index $=1.4$ ) would have a coefficient of 0.75 . Similar variation in

\footnotetext{
${ }^{9}$ Abraham and Hendershott (1996) and Bourassa et al (2001) obtained greater estimates of overshooting because they assumed instantaneous adjustment to changed fundamentals.
} 
city size (5 versus 10 million people) and real income growth rates ( 0 versus 4 percent) would lead to differences in mean reversion of 18 to 30 percent, with the latter occurring in large, high real income growth cities.

High real income growth boosts serial correlation and mean reversion, although the former about three times as much as the latter. Nonetheless, the effects on possible overshooting of real house prices in response to a cycle are not great. High real construction costs, on the other hand, raise serial correlation and lower mean reversion. The combination leads to real house prices continuing to rise beyond their equilibrium values after growth has slowed, causing significant overshooting and eventually a decline in prices. This evidence is consistent with the extreme behavior of house prices in markets such as Los Angeles and Boston in the 1980s, which had large increases in real incomes coupled with high real construction costs over this period.

From a theoretical perspective in which forward-looking prices should immediately incorporate all available information about future changes in real house prices, the impact of factors affecting serial correlation is difficult to explain. Consider first the impact of growth rates of real income and population on the momentum in real price changes (autocorrelation). An efficient market should arbitrage (subject to high transaction costs) the expected cyclical behavior of real prices, dampening cycles and reducing autocorrelation. In this sense, the positive correlation between real construction cost and autocorrelation is instructive. In the absence of complete markets, new construction is one means through which investors 
can exploit inefficient pricing (i.e., home builders can supply more houses when prices exceed their equilibrium level, forcing prices lower). Our results indicate that markets with high construction costs have more autocorrelation.

Like others before us, this paper does not explain why such arbitrage does not occur more quickly. High transaction costs clearly limit the ability of investors to buy housing when its expected future returns are high. However, individual homebuyers and sellers could still incorporate this information in their transactions. Future research could explore the micro evidence on the behavior of individual homebuyers, particularly the role of liquidity, information, and psychology. Lamont and Stein (1999) show that house prices in metro areas with high levels of leverage are more sensitive to income shocks than house prices in metro areas with less leverage. At an individual level, Genesove and Mayer (2001) show that leverage has a large impact on seller reservation prices in a downturn, affecting both the probability of sale, and the subsequent sales prices. Others have shown that liquidity affects refinancing behavior and mobility. While Case and Shiller (1988) use surveys to show that market conditions affect the reported expectations of recent home buyers, few papers have explored the role of information and psychology on expectations formations and transactions prices.

From a policy perspective, this paper suggests ways to reduce the volatility of real house prices. As Shiller (1993) has noted, the development of a futures market could allow investors to buy or sell real estate with much lower transactions cost, ensuring more efficient pricing. In the absence of complete markets, governments 
could reduce barriers to new construction. In the past, many policymakers have viewed developers as part of the problem--feeding the frenzy in a boom. However, new construction is just the market's response to high prices. The findings here demonstrate that lower real construction costs have a role in dampening cycles. Finally, developments in information technology will provide better information to buyers and sellers, allowing them to negotiate more efficient agreements. 


\section{References}

Abraham, Jesse and Patric H. Hendershott. 1993. "Patterns and Determinants of Metropolitan House Prices, 1977-91" in Browne and Rosengreen (eds.), Real Estate and the Credit Crunch, Proceedings of the $25^{\text {th }}$ Annual Federal Reserve Bank of Boston Conference, 18-42.

Research, 7: 191-207.

. 1996. "Bubbles in Metropolitan Housing Markets." Journal of Housing

Blanchard, Olivier and Lawrence Katz. 1992. "Regional Evolutions." Brookings Papers on Economic Activity, 1-61.

Bourassa, Stephen, Patric H.Hendershott and James L. Murphy. 2001. "Further Evidence on the Existence of Housing Market Bubbles." Journal of Property Research, 18. 1-20.

Capozza, Dennis R., Richard Green and Patric H. Hendershott. 1996. "Taxes, Home Mortgage Borrowing and Residential Land Prices" in Aaron and Gale (eds.), Fundamental Tax Reform, The Brookings Institution, Washington D.C., 181-204.

Capozza, Dennis R. and Robert Helsley. 1989. "The Fundamentals of Land Prices and Urban Growth." Journal of Urban Economics, 26: 295-306. . 1990. "The Stochastic City." Journal of Urban Economics, 28: 187-203.

Capozza, Dennis R., Dick Kazarian, and Tom Thomson. 1997. "Mortgage Default in Local Markets." Real Estate Economics, 26: 631-656.

Capozza, Dennis R. and Paul J. Seguin. 1996. "Expectations, Efficiency, and Euphoria in the Housing Market." Regional Science and Urban Economics, 26: 369-386.

Capozza, Dennis R. and Gordon Sick. 1994. "The Risk Structure of Land Markets." Journal of Urban Economics, 35: 297-319.

Case, Karl E. and Robert J Shiller. 1988. "The Behavior of Home Buyers in Boom and Postboom Markets.” New England Economic Review, November/December, 29-46.

. 1989. "The Efficiency of the Market for Single Family Homes." The American Economic Review, 79: 125-37.

Chiang, Raymond, Ian Davidson and John Okunev. 1997. "Some Further Theoretical and Empirical Implications regarding the Relationship between Earnings, Dividends and Stock Prices." Journal of Banking and Finance, 21, 17-35.

DiPasquale, Denise and William Wheaton. 1996. Urban Economics and Real Estate Markets, Prentice-Hall, Englewood Cliffs, NJ.

Fama, Eugene, and Kenneth French. 1988. "Permanent and Temporary Components of Stock Prices.” Journal of Political Economy, 96, 246-273. 
Frankel, Jeffrey, and Andrew Rose. 1996. "A Panel Project on Purchasing Power Parity: Mean Reversion within and between Countries." Journal of International Economics, 40, 209-224.

Genesove, David and Christopher Mayer, 2001. "Loss Aversion and Seller Behavior: Evidence from the Housing Market." The Quarterly Journal of Economics, 116, 1233-60.

Hendershott, Patric H. 2000. "Property Asset Bubbles: Evidence from the Sydney Office Market." Journal of Real Estate Finance and Economics, 20: 67-81.

Hendershott, P.H., and T. Thibodeau. 1993. "The Relationship Between Median and Constant Quality House Prices: Implications for Setting FHA Loan Limits. "Journal of the American Real Estate and Urban Economics Association, 18: 323-334.

Lamont, Owen and Jeremy Stein. 1999. "Leverage and House Price Dynamics in U.S. Cities." RAND Journal of Economics, autumn.

Malpezzi, Steven, 1999. "A Simple Error Correction Model of Housing Prices." Journal of Housing Economics, 8; 27-62.

Mayer, Christopher and Tsur Somerville 2000. "Land Use Regulation and New Construction?" Regional Science and Urban Economics, 30: 639-662.

Poterba, James and Lawrence Summers. 1988. "Mean Reversion in Stock Prices: Evidence and Implications." Journal of Financial Economics, 22: 27-59.

Quan, Daniel C. and John Quigley. 1991. "Price Formation and the Appraisal Function in Real Estate Markets." Journal of Real Estate Finance and Economics, 4: 127-46.

Rose, Louis A. 1989. "Urban Land Supply: Natural and Contrived Restrictions." Journal of Urban Economics, 25: 325-45.

Shiller, Robert. 1990. "Market Volatility and Investor Behavior." The American Economic Review, 80: 58-62.

Shiller, Robert. 1993. Macro Markets. Clarendon Press: Oxford.

Wheaton, William C. 1990. "Vacancy, Search, and Prices in a Housing Market Matching Model." Journal of Political Economy, 98: 1270-92. 


\section{Appendix A: Data Sources and Definitions}

Median sales price of existing homes \& National Association of Realtors Real Estate Outlook; annual data, except that latest year is arithmetic mean of quarterly prices

Metro area population \& Annual mid-year estimate, Bureau of the Census; supplied by the Bureau of Economic Analysis, May, 1995

Total employment, metro area \& Bureau of Economic Analysis May 1995

Nominal personal income per capita \& Bureau of Economic Analysis May 1995

Local area construction cost indexes \& R.S. Means Handbook

State average property tax rates (used in calculating homeowner's \% cost of capital) \& American Council on Intergovernmental Relations Significant Features of Fiscal Federalism, 1994. The property tax series is published only occasionally

National average home mortgage interest rate (used in calculating homeowner's \% cost of capital) \& Economic Report of the President for the current year, or Statistical Abstract of the United States

The annualized Consumer Price Index for all urban consumers (used in deflating income and house prices) \& Electronic edition of the Economic Bulletin Board, October 1995; the rate of change in the previous year is the expected inflation rate used in the user cost calculation 


\section{Appendix B: Metropolitan Areas Included in the Study}

Code name \& Census name

Northern Atlantic Region

Boston \& Boston-Worcester-Lawrence-Lowell-Brocktn, MA-NH (NECMA)

Hartford \& Hartford, CT (NECMA)

Providence \& Providence-Warwick-Pawtucket, RI (NECMA)

New York \& New York-Northern New Jersey-Long Island, NY-NJ-CT-PA (CMSA)

Middle Atlantic Region

Baltimore \& Baltimore, MD (PMSA)

Philadelphia \& Philadelphia, PA-NJ (PMSA)

Washington DC \& Washington, DC-MD-VA-WV (PMSA)

Southeastern Region

Birmingham \& Birmingham (MSA)

Fort Lauderdale \& Fort Lauderdale, FL (PMSA)

Knoxville \& Knoxville, TN (MSA)

Louisville \& Louisville, KY-IN MSA

Memphis \& Memphis, TN-AR-MS MSA

Nashville \& Nashville, TN (MSA)

New Orleans \& New Orleans, LA (MSA)

Tampa \& Tampa-St. Petersburg-Clearwater, FL (MSA)

West Palm Beach \& West Palm Beach-Boca Raton, FL (MSA)

Great Lakes Region

Akron \& Akron, OH (PMSA)

Albany \& Albany-Schenectady-Troy, NY (MSA)

Chicago \& Chicago-Gary-Kenosha, IL-IN-WI (CMSA)

Columbus \& Columbus, OH (MSA)

Detroit \& Detroit-Ann Arbor-Flint, MI (CMSA)

Grand Rapids \& Grand Rapids-Muskegon-Holland, MI (MSA)

Indianapolis \& Indianapolis, IN (MSA)

Milwaukee \& Milwaukee-Waukesha, WI (PMSA)

Minneapolis-St. Paul \& Minneapolis-St. Paul, MN-WI (MSA)

Rochester \& Rochester, NY (MSA)

Saint Louis \& Saint Louis, MO-IL (MSA)

Syracuse \& Syracuse, NY (MSA)

Great Plains Region

Des Moines \& Des Moines, IA (MSA)

Kansas City \& Kansas City, MO-KS (MSA)

Omaha \& Omaha, NE-IA (MSA) 
Southwestern Region

Albuquerque \& Albuquerque, NM (MSA)

El Paso \& El Paso,TX (MSA)

Houston \& Houston-Galveston-Brazoria, TX (CMSA)

Oklahoma City \& Oklahoma City, OK (MSA)

Salt Lake \& Salt Lake City-Ogden, UT (MSA)

San Antonio \& San Antonio, TX (MSA)

Tulsa \& Tulsa, OK (MSA)

Dallas \& Dallas-Fort Worth, TX (CMSA)

Southern California Region

Los Angeles \& Los Angeles-Long Beach, CA (PMSA)

Orange County \& Anaheim-Santa Ana-Garden Grove (Orange County, CA)

Riverside-San Bernadino \& Riverside-San Bernardino, CA (PMSA)

San Diego \& San Diego, CA (MSA)

Northern Pacific Region

San Francisco \& San Francisco-Oakland, CA (CMSA) 
Table 1. Summary Statistics

\begin{tabular}{|l|l|l|l|l|}
\hline \hline & Mean & $\begin{array}{l}\text { Standard } \\
\text { Deviation }\end{array}$ & Minimum & Maximum \\
\hline Real Price & 72,000 & 27,000 & 41,000 & 210,000 \\
\hline Change in Real Price & $0 \%$ & $5 \%$ & $-14 \%$ & $29 \%$ \\
\hline Population & $2,300,000$ & $3,100,000$ & 370,000 & $20,000,000$ \\
\hline $\begin{array}{l}5 \text { Year Change in } \\
\text { Population }\end{array}$ & $7 \%$ & $7 \%$ & $-6 \%$ & $31 \%$ \\
\hline Real Personal Income & 13,900 & 2,200 & 7,700 & 22,000 \\
\hline $\begin{array}{l}\text { Change in Real Personal } \\
\text { Income }\end{array}$ & $1 \%$ & $2 \%$ & $-7 \%$ & $12 \%$ \\
\hline $\begin{array}{l}\text { Real Construction Cost } \\
\text { Index }\end{array}$ & 0.97 & 0.10 & 0.78 & 1.5 \\
\hline \begin{tabular}{l} 
User Cost \\
\hline \begin{tabular}{l} 
Land Supply Index \\
\hline
\end{tabular}
\end{tabular} & 0.89 & 0.13 & 0.54 & $1 \%$ \\
\hline
\end{tabular}


Table 2. Steady State Regression. Dependent variable is the log of real price. OLS estimates of equation 1 in the text. Model 2 is estimated with fixed effects.

\begin{tabular}{|c|c|c|c|c|}
\hline & \multicolumn{2}{|l|}{$\begin{array}{l}\text { Model } 1 \\
\text { OLS }\end{array}$} & \multicolumn{2}{|c|}{$\begin{array}{l}\text { Model } 2 \\
\text { Fixed Effects }\end{array}$} \\
\hline & Coefficient & T-Statistic & Coefficient & T-Statistic \\
\hline Log of Population & 0.07 & 7.7 & 0.15 & 2.9 \\
\hline Log of Real Median Income & 0.45 & 9.7 & 0.43 & 5.3 \\
\hline Real Construction Cost & 1.10 & 14.8 & 1.20 & 13.9 \\
\hline $\begin{array}{l}5 \text {-Year \% Change in } \\
\text { Population }\end{array}$ & 1.53 & 16.4 & 1.54 & 13.9 \\
\hline Log of User Cost & -0.04 & -3.1 & -.09 & -3.2 \\
\hline Land Supply Index & -0.38 & -7.6 & & \\
\hline Fixed Effects (City, Year) & No & & Yes & \\
\hline $\mathrm{R}^{2}$ & 0.65 & & 0.43 & \\
\hline
\end{tabular}




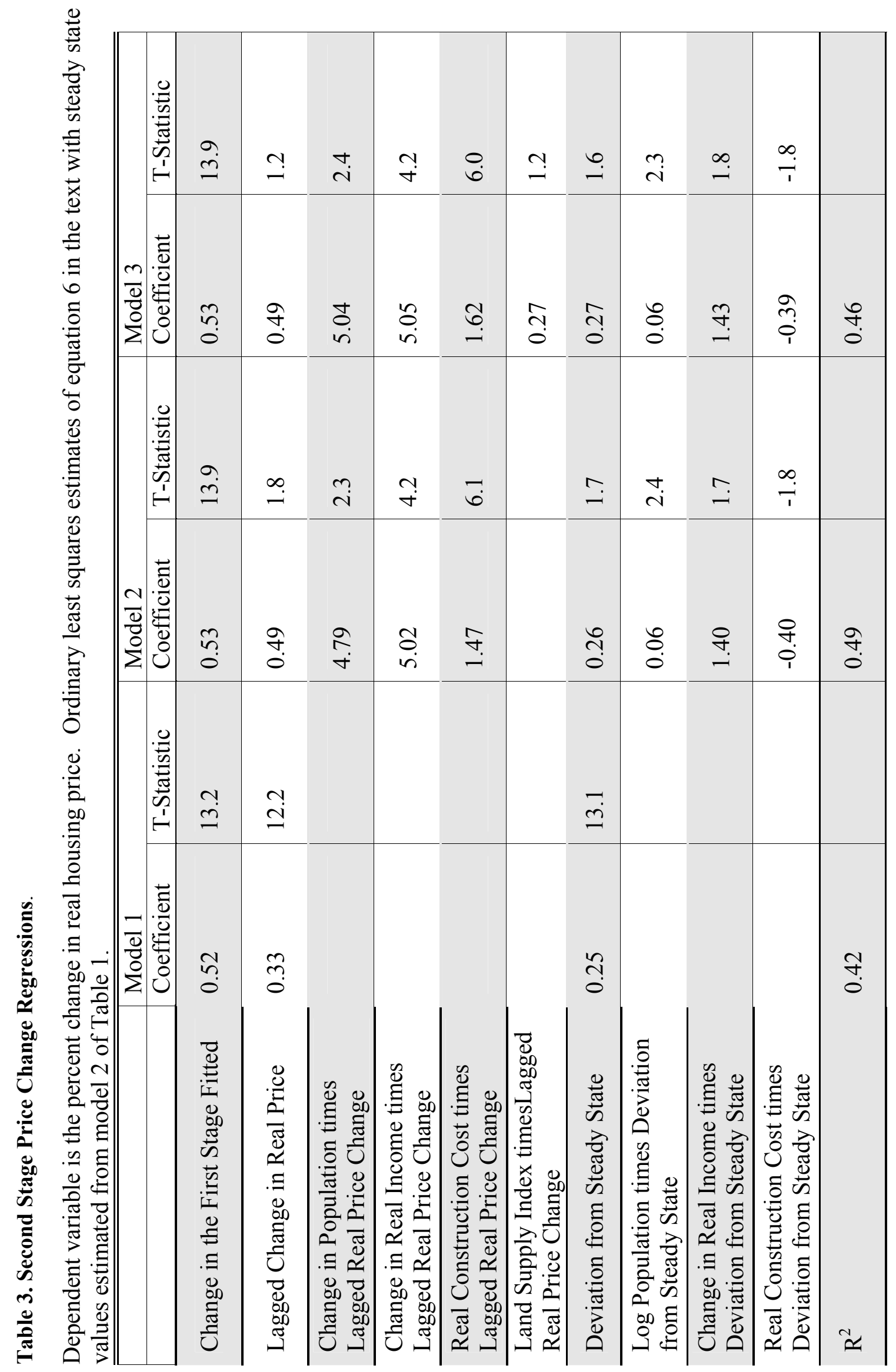


Table 4: Maximum Overshooting for Different Adjustment Parameters in Response to Six Years of Four Percent Growth in the Equilibrium Price

Mean Reversion Parameter ( $\beta$ )

\begin{tabular}{|c|c|c|c|c|}
\hline $\begin{array}{l}\text { Adjustment } \\
(\gamma)\end{array}$ & $\begin{array}{l}\text { Autocorrelation } \\
(\alpha)\end{array}$ & 0.1 & 0.3 & 0.5 \\
\hline 0.5 & 0.5 & 2 & 3 & 2 \\
\hline 0.5 & 0.67 & 8 & 6 & 4 \\
\hline 0.75 & 0.5 & 8 & 5 & 3 \\
\hline 0.75 & 0.75 & 24 & 12 & 7 \\
\hline 0.5 & 0.9 & 27 & 14 & 8 \\
\hline
\end{tabular}


Figure 1. The dynamic behavior of the difference equation.

This graph illustrates the parameter values that generate housing cycles when fundamentals are shocked. Values of the autocorrelation coefficient greater than 1 result in explosive behavior. Parameter values that lie below the curve result in cycles.

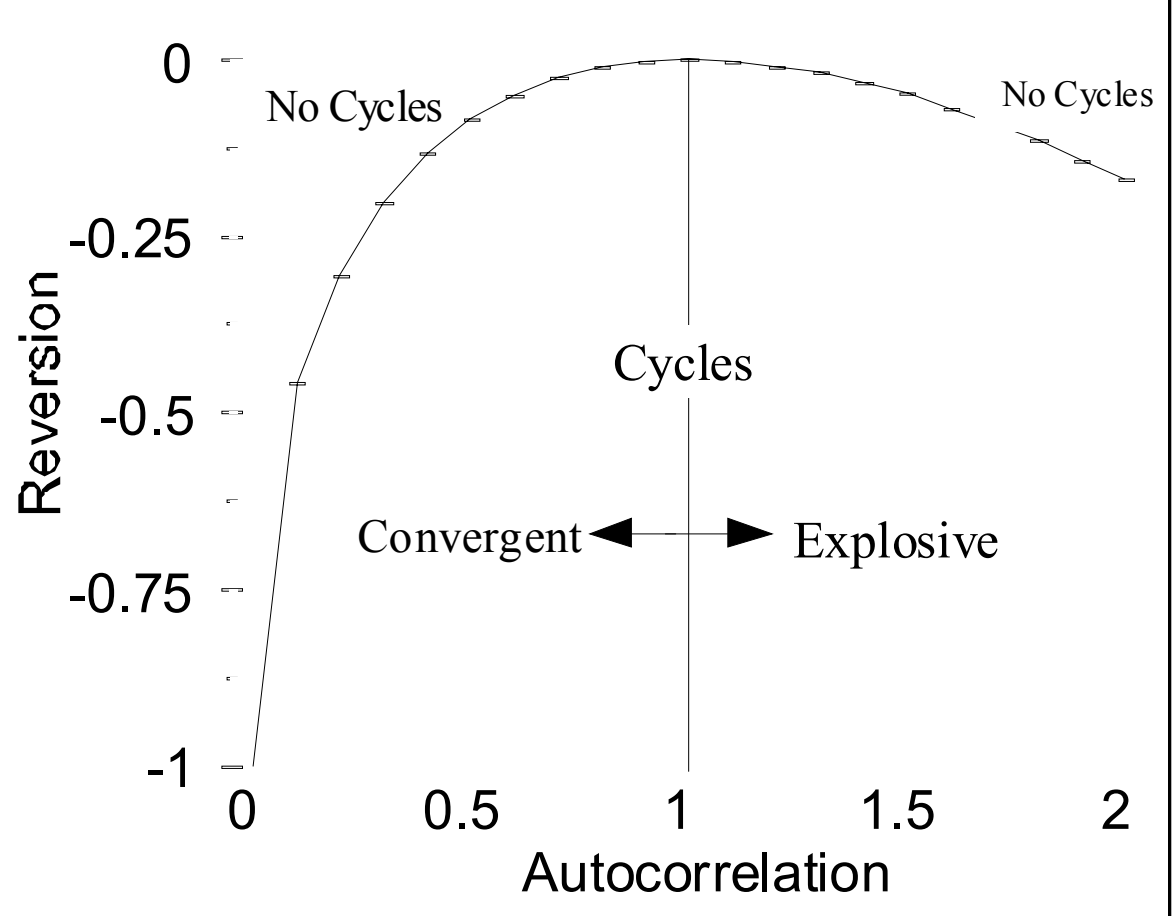

